\title{
Monoclonal antibodies against Aeromonas salmonicida lipopolysaccharide identify differences among strains
}

\author{
D. D. Rockey ${ }^{1}$, C. F. Dungan ${ }^{1, *}$, T. Lunder ${ }^{2}$, J. S. Rohovec ${ }^{1 * *}$ \\ ${ }^{1}$ Department of Microbiology, Oregon State University, Corvallis, Oregon 97331, USA \\ ${ }^{2}$ National Veterinary Institute, PO Box 8156, Dept N-0033 Oslo 1, Norway
}

\begin{abstract}
Monoclonal antibodies (MAbs) directed against Aeromonas salmonicida salmonicida lipopolysaccharide (LPS) were produced and characterized. The specificity of the MAbs $(N=4)$ to LPS was determined by examination of western blots of proteinase $\mathrm{K}$-treated whole cell preparations of $\mathrm{A}+$ and $\mathrm{A}$ - strains, i.e. strains with and without a major surface protein layer, the A layer. The different MAbs identified different epitopes on A salmonicida LPS. Three of the 4 MAbs (MAb 1, C, and D) reacted with all but a unique group of $A$. salmonicida strains tested. These MAbs also had binding properties that were insensitive to periodate oxidation of antigen. The fourth MAb (MAb 6) reacted with a more limited collection of bacterial isolates and the binding was sensitive to periodate treatment of antigen. These data demonstrated that heterogeneity is present in the LPS of this species. Lipopolysaccharide from all tested isolates of $A$. salmonicida salmonicida $(N=10)$ and $A$. salmonicida masoucida $(N=2)$ reacted with each $M A b$, while isolates of $A$. salmonicida achromogenes $(N=6)$ reacted with MAbs 1, C, and D but not with MAb 6. No patterns of similarity were apparent when unclassified isolates of A. salmonicida were examined.
\end{abstract}

\section{INTRODUCTION}

Aeromonas salmonicida, the etiologic agent of furunculosis and ulcer disease of salmonids and other fishes, causes major losses in cultured fish in many parts of the world (Snieszko et al. 1950, Bootsma et al. 1977. McCarthy \& Roberts 1980). Considerable research effort has been expended to investigate means of preventing furunculosis in hatchery stocks. Efficacious vaccines have been reported, but their ability to stimulate a protective specific immune response is under debate (Ellis 1988). Therefore, these diseases are currently controlled by antibiotic therapy and pathogen avoidance.

Both cellular and secreted antigens of Aeromonas salmonicida have been investigated as possible immunogens (Munro 1984, Hastings \& Ellis 1988). Immunologically important cellular antigens include

\footnotetext{
- Present address: Cooperative Oxford Laboratory, $904 \mathrm{~S}$ Morris St., Oxford, Maryland 21654, USA

- Addressee for correspondence
}

the A layer (McCarthy et al. 1983) and lipopolysaccharide (LPS; Paterson \& Fryer 1974). Uniformity of these 2 components was reported within the species (Chart et al. 1984, Kay et al. 1984)

Three subspecies of Aeromonas salmonicida are currently recognized. These are $A$. salmonicida salmonicida, A. salmonicida achromogenes, and A. salmonicida masoucida (Popoff 1984). However, many isolates do not fit into any of these categories and modifications to the current classification scheme have been proposed (McCarthy \& Roberts 1980, Belland \& Trust 1988, Austin et al. 1989). These proposals include the addition of a new subspecies. A. salmonicida nova, and combining most of the isolates from $A$. salmonicida masoucida and A. salmonicida achromogenes into a single subspecies with the latter epithet.

The present paper describes the production and characterization of monoclonal antibodies (MAbs) against Aeromonas salmonicida LPS. These MAbs were used to identify LPS heterogeneity within the species. Additionally, reactivity patterns were differrent among the different subspecies of $A$. salmonicida. 


\section{MATERIALS AND METHODS}

Bacterial isolates and antigen preparation. All isolates were grown on brain heart infusion ( $\mathrm{BHI}$; Difco Laboratories, Detroit, MI, USA) agar for isolation and were stored at $4{ }^{\circ} \mathrm{C}$ on $\mathrm{BHI}$ agar slants. Isogenic $\mathrm{A}$ layer negative $(A-)$ mutants were selected by growing wild type $(\mathrm{A}+)$ Aeromonas salmonicida strains on Coomassie brillant blue agar at $30^{\circ} \mathrm{C}$ and recovering white colonies (Ishiguro et al. 1981, Wilson \& Horne 1986). Whole cell extracts for electrophoresis and western blotting were prepared from cultures grown in $\mathrm{BHI}$ broth for 24 to $48 \mathrm{~h}$ at $17^{\circ} \mathrm{C}$. Cells were pelleted by centrifugation, washed in phosphate-buffered saline (PBS; $10 \mathrm{mM} \mathrm{PO}_{4}, 150 \mathrm{mM} \mathrm{NaCl}$, pH 7.0) and resuspended in $\Gamma D S$ at ca $10^{9}$ cells mil ${ }^{-1}$. The suspeñsions were kept on ice and sonically lysed with two $10 \mathrm{~s}$ bursts using a probe sonicator with power level at $60 \mathrm{~W}$. Subsamples of these sonicates were mixed with equal volumes of sample buffer (Schleif \& Wensink 1981), boiled for $2 \mathrm{~min}$, and stored at $-20^{\circ} \mathrm{C}$. The remaining sonicate was stored at $-70^{\circ} \mathrm{C}$ for future use or confirmatory analyses.

Selected whole cell sonicates $\left(0.5 \mathrm{mg} \mathrm{m}^{-1} \mathrm{PBS}\right)$ were treated with proteinase K (Sigma Chemical Co. St Louis, $\mathrm{MO}$ ) for $4 \mathrm{~h}$ at room temperature. Digestion was confirmed using SDS-polyacrylamide gel electrophoresis (PAGE) followed by Coomassie brilliant blue staining. These proteinase $\mathrm{K}$ preparations were used as antigen in western blots.

Production of monoclonal antibodies. Viable strain RC 1 (Aeromonas salmonicida salmonicida) bacterial cells harvested from a BHI broth culture were washed in sterile PBS and adjusted to an optical density $\left(\mathrm{A}_{525}\right)$ of 1.0. These live cells were mixed with an equal volume of Freund's complete adjuvant (FCA) and $0.5 \mathrm{ml}$ was injected subcutaneously into female $\mathrm{Balb} / \mathrm{C}$ mice. One hundred microliters of an identical antigen preparation without FCA was injected intraperitoneally $21 \mathrm{~d}$ after the primary injection. Three days after the secondary injection, spleen cells were harvested and fused with $\mathrm{Sp} 2 / 0$ myeloma cells as described by Campbell (1984). Clones producing MAbs against wild type Aeromonas salmonicida cells were selected using an antibody capture ELISA with $\mathrm{A}+\mathrm{A}$. salmonicida strain RC 1 cells as antigen (Campbell 1984), expanded, and cloned twice by limiting dilution. All MAbs were harvested from tissue culture. Heavy and light chain isotypes and subisotypes were determined using a commercial kit (Bio-Rad Laboratories, Richmond, CA).

Electrophoresis and western blots. Polyacrylamide gel electrophoresis was performed on each isolate used for antigenic analysis. Unless otherwise indicated, ca $3 \times 10^{6}$ sonically lysed bacteria were mixed with sam- ple buffer (Schleif \& Wensink 1981) and electrophoresed using a Bio-Rad Mini-Protean II electrophoresis apparatus. Gels were stained for total protein with Coomassie brilliant blue and for LPS using the silver stain technique of Tsai \& Frasch (1982). Western blots of cell lysates were performed with a Bio-Rad Laboratories Mini-Transblot apparatus. After transfer, blots were blocked with $3 \%$ bovine serum albumin (BSA) in tris-buffered saline (TBS; $150 \mathrm{mM} \mathrm{NaCl}, 50$ mM tris $\mathrm{pH} 8.0$ ) plus $0.1 \%$ Tween-20 (TTBS). Blots were then washed once in TTBS and tissue culture supernatant of the appropriate hybridoma was applied. Blots at each step were incubated at room temperature for $1 \mathrm{~h}$. After incubation, the blots were washed 3 times in TTBS and incubated in goat anti-mouse immunoglubulin aniiser conjugded to horseradish peroxidase (Hyclone Laboratories, Logan, UT). Blots were washed 3 times in TTBS and once in TBS, and then developed with 4-chloro-naphthol (4CN) and hydrogen peroxide $\left(0.5 \mathrm{mg} \mathrm{ml}^{-1} 4 \mathrm{CN}\right.$ and $0.03 \% \mathrm{H}_{2} \mathrm{O}_{2}$ ).

Periodate treatment of blots to determine epitope sensitivity to oxidation was performed as described (Woodward et al. 1985). Briefly, blots were incubated in TTBS after transfer and then incubated in $10 \mathrm{mM}$ periodic acid in $50 \mathrm{mM}$ sodium acetate $(\mathrm{pH} 4.5)$ for $1 \mathrm{~h}$ in the dark. Blots were rinsed in $50 \mathrm{mM}$ sodium acetate and incubated in $50 \mathrm{mM}$ sodium borohydride in PBS. Control blots were incubated in $50 \mathrm{mM}$ sodium acetate without periodate. After treatment with borohydride, the primary antibody was added to all blots and incubations proceeded as with untreated blots.

\section{RESULTS}

\section{Characterization of monoclonal antibodies}

Four MAbs were produced and characterized. Three were of the $\operatorname{IgG}_{2 b}$ subisotype with $\kappa$ light chains (MAb $1, C$, and D). One was of the IgM isotype with a $\mathrm{K}$ light chain (MAb 6). The MAbs were reacted with selected antigen preparations to examine their binding specificity. Western blots using proteinase $K$ treated antigens and blots using $\mathrm{A}$ - derivatives of isolate RC1 showed that each MAb bound Aeromonas salmonicida LPS (Fig. 1).

Periodate treatment prior to western blotting demonstrated that the epitope bound by MAb D was periodate-insensitive and the epitope bound by MAb 6 was periodate-sensitive (Fig. 2). MAbs 1 and $C$ reacted similarly to MAb D.

Three patterns were observed when the MAbs were reacted with different Aeromonas salmonicida isolates in western blots (Fig, 3). Isolates reacted with both MAb D and MAb $6(+/+$ reaction $)$, or with MAb D but 


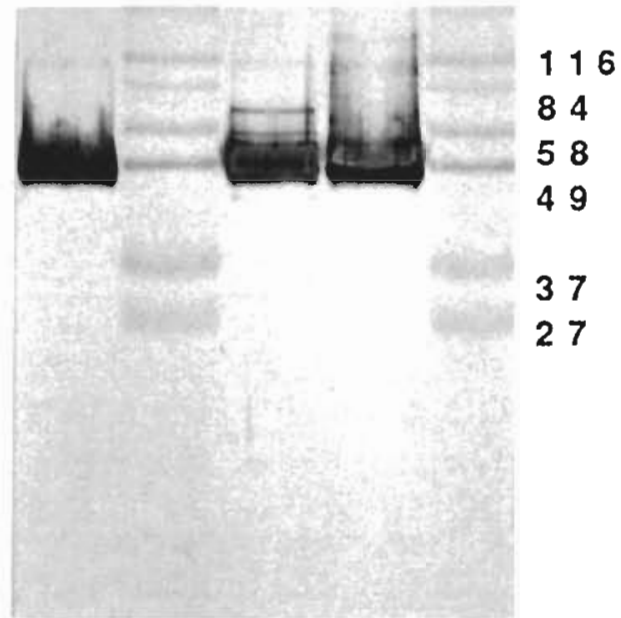

\section{Std $2 \quad 3 \quad$ Std}

Fig. 1. Western blot of Aeromonas salmonicida isolate RC 1 cell preparations using MAb D as probe. Std: protein molecular weights, values in kilodaltons. (1) A layer - cells; (2) proteinase $\mathrm{K}$ treated $\mathrm{A}$ layer + cells; (3) untreated A layer + cells

not MAb $6(+/-$ reaction $)$, or the isolates reacted with neither antibody $(-1-$ reaction). Several isolates were also tested with MAb 1 and MAb $C$ and the pattern was identical to MAb D. All isolates that reacted with $\mathrm{MAb}$ 6 also reacted with MAb D. Isolates that did not react with MAb D ( $-/$ - strains) also did not react with rabbit antiserum directed against LPS from $A$. salmonicida salmonicida strain RC 1, Lipopolysaccharide from all isolates with MAb $\mathrm{D}$ were recognized by this rabbit antiserum. The Norwegian strains that were - / - (2013 and 2779) were shown by electrophoresis and subsequent silver staining to lack LPS O polysaccharide chains
The results demonstrated that reactivity varied among isolates (Table 1). Comparisons among previously classified subspecies of Aeromonas salmonicida demonstrated that all tested $A$. salmonicida salmonicida (10 isolates) were $+/+$, strains of $A$. salmonicida achromogenes ( 6 isolates) were $+1-$, and the 2 A. salmonicida masoucida isolates were $+/ t$. Reactivity patterns were not apparent in tested unclassified isolates.

The unclassified isolates harvested from fish in Norway were examined biochemically to determine their relationship to established taxonomic groups. Each of these isolates produced acid from sucrose and glucose. Pigment and indole production were variable and did not correlate directly with MAb reactivity (Table 2).

Antibodies were also used as probes in western blots of sonicates of other bacterial fish pathogens. This examination included strains of Aeromonas hydrophila, Yersinia ruckeri, Pseudomonas fluorescens, Edwardsiella sp., Vibrio anguillarum, Carnobacterium piscicola and Renibacterium salmoninarum. Neither MAb D nor MAb 6 reacted with these bacteria in western blots (data not shown).

\section{DISCUSSION}

We have produced MAbs against Aeromonas salmonicida salmonicida LPS which differentiate among isolates of $A$. salmonicida. These MAbs, produced against viable $A$. salmonicida emulsified in FCA, reacted specifically with $A$. salmonicida LPS and did not cross-react with other tested bacterial pathogens of fish. The MAbs were used exclusively for western blotting in the described research but they also can be used for enzyme-linked immunosorbent assays (ELISAs) and in 'dot-blot' immunoassays (not shown).
Fig. 2. Periodate treated and untreated western blots of Aeromonas salmonicida salmonicida isolate MLE-2 probed with MAb D or 6. Lanes: $(1,4,5,7)$ protein molecular weight standards for reference purposes; (2) untreated blot probed with MAb D; (3) treated blot probed with MAb D; (6) untreated blot probed with MAb 6; (8) treated blot probed with MAb 6
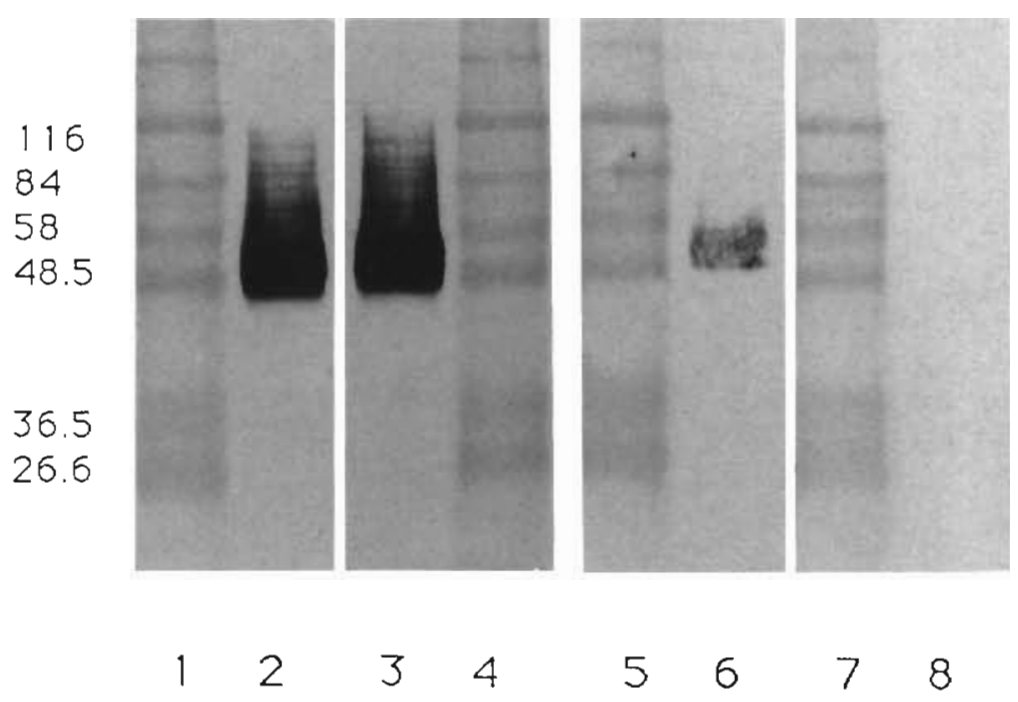

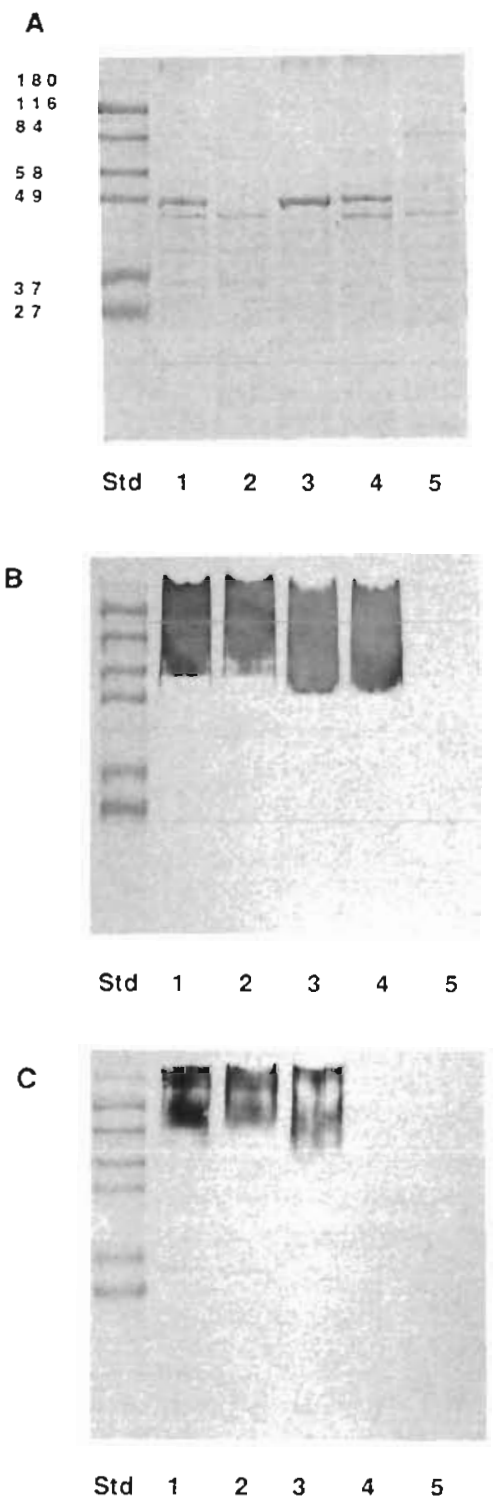

Fig. 3. (A) Polyacrylamide gel of selected Aeromonas salmonicida isolates; $(B)$ western blot using MAb D as probe; (C) western blot using MAb 6 as probe. In each photograph the order is as follows: Std: molecular weight standards in kilodaltons; (1) A layer + RC 1; (2) A layer - RC 1; (3) 3173 ;

(4) $2764 ;(5) 2779$

The MAbs were differentiated on the basis of their isotype, binding sensitivity to periodate oxidation of antigen, and reactivity with selected Aeromonas salmonicida isolates. The binding of antigen by MAbs 1 , $C$, and D ( 3 independent $\gamma_{2 b}, \kappa$ clones) was insensitive to periodate oxidation of antigen, whereas the binding of antigen by MAb $6(\mu, \kappa)$ was sensitive to this treatment. The reactivity of the MAbs in western blots with preparations of different $A$. salmonicida isolates as antigen showed that the majority of isolates reacted with MAbs 1, C, and D while a subset of these isolates reacted with $M A b 6$. All isolates which reacted with MAbs 1, C, and D also reacted with rabbit antiserum produced against $A$. salmonicida salmonicida strain $\mathrm{RC}$ 1. No isolates were identified that reacted only with MAb 6. Certain isolates did not react with any of the MAbs. Tested strains from this group did not have high molecular weight LPS chains.

Other MAbs against components of the Aeromonas salmonicida cell surface have been reported (Chart et al. 1984, Goerlich et al. 1984, Kay et al. 1984). Chart et al. (1984) used an anti-LPS MAb in their comparison of the structure and immunogenicity of different isolates of A. salmonicida. They showed that all strains with high molecular weight LPS reacted with the IVIAb. They used these and other data to support the conclusion that $A$. salmonicida LPS is structurally and immunochemically homogeneous. In this paper we demonstrated that LPS has antigenic variation among isolates. Such variability is common within Gram-negative bacterial species and the degree of identified heterogeneity within $A$. salmonicida is comparatively small (Ezura et al, 1980, Le Minor 1984). It is possible that future analyses will identify other variable epitopes within the species.

Western blots performed using different concentrations of antigen demonstrated that the appearance of the blot was dependent upon the concentration of antigen electrophoresed and transferred. This is shown by the differences between the banding patterns in certain blots (Figs. 1 \& 3). Higher concentrations were used in the determination of reactivity (Fig. 3) because lower concentrations commonly resulted in questionable reactions.

The classification of isolates into specific subspecies of Aeromonas salmonicida may be facilitated by examination with the MAbs. In our analyses, all isolates of the subspecies $A$. salmonicida salmonicida were $+/+$. These included isolates from North America, Europe, and Korea. Strains identified as A. salmonicida achromogenes strains, including type strain NCMB 1110 , were $+/-$, and the 2 A. salmonicida masoucida strains (including the type strain) were $+/+$. Isolates referred to as unclassified had no consistent reactivity pattern. These isolates were taken from fish in Europe, Japan, North America, and Australia. Other authors have recently performed rigorous analyses of the systematics of this organism and each has discussed the creation of new subspecies within the species (McCarthy \& Roberts 1980, Belland \& Trust 1988, Austin et al. 1989). Analyses are continuing to determine the utility of these MAbs for accurately assessing the validity of the current and proposed classification schemes for $A$. salmonicida. 
Table 1 Reaction of MAbs D and 6 by western blotting with selected isolates of Aeromonas salmonicida

\begin{tabular}{|c|c|c|c|c|c|}
\hline Isolate & Subspecies $^{a}$ & Host $^{b}$ & $\mathrm{D}$ & 6 & Reference or source \\
\hline ATCC 14174 & sal $\mathrm{T}^{\mathrm{C}}$ & BT & + & + & A.T.C.C. \\
\hline $\mathrm{RC} 1$ & sal & $\mathrm{Ch}$ & + & + & Rockey et al. (1988) \\
\hline SS 70 & sal & $\mathrm{Ch}$ & + & + & Udey \& Fryer (1978) \\
\hline MLE-2 & sal & MS & + & + & Fryer et al. (1988) \\
\hline 567 & sal & AS & + & + & N.V.I. ${ }^{d}$ \\
\hline 2683 & sal & AS & + & + & N.V.I. \\
\hline 3173 & sal & AS & + & + & N.V.I. \\
\hline $77 / 88$ & sal & $\mathrm{Br}$ & + & + & E. M. Bernoth \\
\hline MT 518 & sal & AS & + & + & T Hastings \\
\hline MT 194 & sal & AS & + & + & T Hastings \\
\hline NCMB 1110 & ach $\mathrm{T}$ & $\mathrm{Br}$ & + & - & N.V.I. \\
\hline MT 533 & ach & AS & + & - & $\mathrm{T}$ Hastings \\
\hline 362 & $a c h$ & AS & + & - & N.V.I. \\
\hline 937 & $a c h$ & AS & + & - & N.V.I. \\
\hline 797 & $a c h$ & AS & + & - & N.V.I. \\
\hline 2778 & ach & AS & + & - & N.V.I. \\
\hline ATCC 27013 & $\operatorname{mas} \mathrm{T}$ & MS & + & + & Kimura (1969) \\
\hline $2 \mathrm{~b} 1$ & mas & MS & + & + & M. Yoshimizu \\
\hline 865 & Uncl. & $\mathrm{Br}$ & + & + & N.V.I. \\
\hline 1391 & Uncl. & WF & + & + & N.V.I. \\
\hline 2221 & Uncl. & BT & + & + & N.V.I. \\
\hline 1977 & Uncl. & AS & + & + & N.V.I. \\
\hline 2120 & Uncl. & $\mathrm{Br}$ & + & - & N.V.I. \\
\hline 2764 & Uncl. & AS & + & - & N.V.I. \\
\hline $\mathrm{O} 2$ & Uncl. & Ayu & + & - & M. Yoshimizu \\
\hline As 7 & Uncl. & $\mathrm{GF}$ & + & - & Elliott \& Shotts (1980) \\
\hline $\operatorname{Ar} 57$ & Uncl. & GF & - & - & Tajima et al. (1987) \\
\hline 2013 & Uncl. & AS & - & - & N.V.I. \\
\hline 2779 & Uncl. & AS & - & - & N.V.I. \\
\hline $5602(A 405)^{e}$ & Uncl. & $\mathrm{GF}$ & - & - & Trust et al. (1980) \\
\hline $5603(\mathrm{~A} 404)$ & Uncl. & GF & - & - & Trust et al. (1980) \\
\hline \multicolumn{6}{|c|}{$\begin{array}{l}\text { Subspecies codes: sal, A. salmonicida salmonicida; ach, A. salmonicida achromogenes; mas, A. salmonicida masoucida; } \\
\text { uncl., unclassified A. salmonicida } \\
\text { b Host codes: Ch, chinook salmon Oncorhynchus tschawytscha; MS, Masou salmon O. masou; BT, brook trout Salvelinus } \\
\text { fontinalis; AS, Atlantic salmon Salmo salar; Br, brown trout Salmo trutta; WF, whitefish Coregonus sp.; ayu, Plecoglossus } \\
\text { altivelis; GF, goldfish Carasius auratus } \\
\text { cIndicates type strain } \\
\text { a National Veterinary Institute, Oslo, Norway } \\
\text { e Other common designations are indicated in parentheses }\end{array}$} \\
\hline
\end{tabular}

Table 2. Biochemical characteristics of selected unclassified isolates

\begin{tabular}{|c|c|c|c|c|c|c|c|c|c|c|}
\hline & \multicolumn{10}{|c|}{ Strain } \\
\hline & 865 & 1391 & 2221 & 1977 & 2120 & 2764 & 2778 & 2013 & 2779 & As $7^{\circ}$ \\
\hline MAb group & $+1+$ & $+/+$ & $+1+$ & $+/+$ & $+1-$ & $+1-$ & $+/-$ & $-1-$ & $-1-$ & $+1-$ \\
\hline Acid from sucrose & + & + & + & + & + & + & + & + & + & + \\
\hline Acid from glucose & + & + & + & + & + & + & + & + & + & + \\
\hline Pigment & - & - & - & - & + & + & + & + & - & - \\
\hline Indole & + & + & + & - & + & + & + & + & + & + \\
\hline
\end{tabular}

Acknowledgements. We thank the individuals referenced in Table 1, particularly D. Elliott, who contributed isolates for this study. We also acknowledge J. L. Fryer for direction during the study and for assistance in the preparation of the text, and
T. Nakai for review of the manuscript. Principal funding for this research was received from USDA Science and Engineering grant no. 85-CRSR-2-2578. Oregon Agriculture Experiment Station Technical Paper No. 8936. 


\section{LITERATURE CITED}

Austin, D. A., McIntosh, D., Austin, B. (1989). Taxonomy of fish associated Aeromonas spp. with the description Aeromonas salmonicida subsp. smithia subsp. nov. System. Appl. Microbiol. 11: 277-290

Belland, R. J, Trust, T J. (1988). DNA: DNA reassociation analysis of Aeromonas salmonicida. J. gen. Microbiol. 134: $307-315$

Bootsma, R., Fijan, N., Blommaert, J. (1977). Isolation and primary identification of the causative agent of carp erythrodermatitis. Vet. Archiv. 47: 291--302

Campbell, A. M. (1984). Monoclonal antibody technology. In: Burdon, R. H., van Knippenberg, P. H. (eds.) Laboratory techniques in biochemistry and molecular biology, Vol. 13 Elsevier Science Publishing, New York, p. 120-139

Chart, H., Shaw, D. H., Ishiguro, E. E., Trust, T. J. (1984). Structural and immunochemical homogeneity of Aeromonas salmonicida lipopolysaccharide. J. Bacteriol. 158: $16-22$

Ellis, A. E. (1988). Current aspects of fish vaccination. Dis. aquat. Org. 4: 159-164

Elliott, D. G., Shotts, E. B. (1980). Aetiology of an ulcerative disease in goldfish Carassius auratus (L): microbial examination of diseased fish from seven locations. J. Fish Dis. 3 : $133-143$

Ezura, Y., Tajima, K., Yoshimizu, M., Kimura, T. (1980) Studies on the taxonomy and serology of causative organisms of fish vibriosis. Fish Pathol. 14: 167-179

Fryer, J. L., Hedrick, R. P., Park, J. W., Hah, Y C. (1988) Isolation of Aeromonas salmonicida from masu salmon in the Republic of Korea. J. Wild. Dis. 24: 364-365

Goerlich, R., Schlusener, H. J., Lehmann, J., Greuel, E. (1984). The application of monoclonal antibodies to diagnosis of Aeromonas salmonicida infections in fishes. Bull. Eur. Ass. Fish Pathol, 4 (4): 66

Hastings, T. S., Ellis, A. E. (1988). The humoral immune response of rainbow trout, Salmo gairdneri Richardson, and rabbits to Aeromonas salmonicida extracellular products. J. Fish Dis. 11: 147-160

Ishiguro, E. E., Kay, W. W., Ainsworth, T., Chamberlain, J. B. Austen, R. A., Buckley, J. T., Trust, T. J. (1981). Loss of virulence during culture of Aeromonas salmonicida at high temperature. J. Bacteriol. 148: 333-340

Kay, W. W., Phipps, B. M., Ishiguro, E. E., Olafson, R. W. Trust, T. J. (1984). Surtace layer virulence A-proteins from Aeromonas salmonicida strains. Can. J. Biochem. Cell Biol. 62: $1064-1071$

Kimura, T (1969). A new subspecies of Aeromonas salmonicida as an etiologic agent of furunculosis on

Responsible Subject Editor. T. Evelyn, Nanaimo, B. C., Canada
'Sakuramasu' (Oncorhynchus masou) and pink salmon ( $O$. gorbuscha) rearing for maturity. Part 1: On the morphological and physical properties. Fish Pathol. 3: 34-44

Le Minor, L. (1984). Genus III. Salmonella. In: Krieg, N. R., Holt, J. G. (eds.) Bergey's manual of systematic microbiology, vol. 1. Williams and Wilkins, Baltimore, p. 427-458

McCarthy, D. H. Amend, D. F., Johnson, K. A., Bloom J. V. (1983). Aeromonas salmonicida: determination of an antigen associated with protective immunity and evaluation of an experimental bacterin. J. Fish Dis. 6: 155-174

McCarthy, D. H., Roberts, R. J. (1980). Furunculosis of fish the present state of our knowledge. Adv. aquat. Microbiol. 2: $283-341$

Munro, A. L. S. (1984). A furunculosis vaccine - illusion or achievable objective In: de Kinkelin, P. (ed.) OIE symposium on fish vaccination. O.I.E., Paris, p. 97-120

Paterson, W D., Fryer, J. L. (1974). Effect of temperature and antigen dose on the antibody response in juvenile coho salmon (Oncorhychus kisutch) to Aeromonas salmonicida endotoxin. J. Fish. Res. Bd Can. 31: 1743-1749

Popoff, M. (1984). Genus III. Aeromonas. In: Krieg, N. R., Holt, J. G. (eds.) Bergey's manual of systematic bacteriology, Vol. I. Williams and Wilkins, Baltimore, p. 545-548

Rockey, D. D., Fryer, J. L., Rohovec, J. S. (1988). Separation and in vivo analysis of two proteases and T-hemolysin of Aeromonas salmonicida. Dis. aquat. Org. 5: 197-204

Schleif, R. F., Wensink, P. C. (1981). Practical methods in molecular biology. Springer-Verlag, New York

Snieszko, S. F., Griffin, P. J., Friddle, S. B. (1950). A new bacterium (Hemophilus piscium n. sp.) from ulcer disease of trout. J. Bacteriol. 59: 699-710

Tajima, K., Ezura, Y, Kimura, T. (1987). Pathogenicity of a non-protease secreting strain of Aeromonas salmonicida. Bull. Fac. Fish. Hokkaido Univ. 38: 139-150

Trust, I J., Khouri, A. G., Austen, R. A., Ashburner, L. D. (1980). First isolation of atypical Aeromonas salmonicida in Australia. FEMS Microbiol. Lett. 9: 39-42

Tsai, C. M., Frasch, C. E. (1982). A sensitive silver stain for detecting lipopolysaccharide in polyacrylamide gels. Analyt. Biochem. 119: 115-119

Udey, L. R., Fryer, J. L. (1978). Immunization of fish with bacterins of Aeromonas salmonicida. Mar. Fish. Rev. 40: $12-17$

Wilson, A., Horne, M. T. (1986). Detection of A-protein in Aeromonas salmonicida and some effects of temperature on A-layer assembly. Aquaculture 56: 23-27

Woodward, M. P., Young, W. W. Jr, Bloodgood, R. A. (1985). Detection of monoclonal antibodies specific for carbohydrate epitopes using periodate oxidation. J. Immunol. Meth. 78: 143-153

Manuscript first received: September 13, 1989

Revised version accepted: January 9, 1991 